\title{
Tingkat Kesejahteraan Berdasarkan Proporsi Konsumsi Pangan Petani Plasma Kelapa Sawit di Desa Pangkalan Tiga Kecamatan Pangkalan Lada Kabupaten Kotawaringin Barat
}

\section{(Welfare Level Based on Proportion of Food Consumption of Palm Oil Plasma Farmers in Pangkalan Tiga Village Pangkalan Lada District Kotawaringin Barat Regency)}

\author{
Novi Nurhayati \\ Program Studi Agribisnis, Fakultas Pertanian, Universitas Antakusuma Pangkalan Bun \\ noviuntama@gmail.com
}

\begin{abstract}
ABSTRAK
Penelitian ini bertujuan untuk mengetahui tingkat kesejahteraan rumah tangga petani sawit di Desa Pangkalan Tiga Kecamatan Pangkalan Lada Kabupaten Kotawaringin Barat. Proporsi konsumsi makanan merupakan salah satu indikator untuk menentukan tingkat kesejahteraan rumah tangga. Penelitian ini menggunakan data primer dan data sekunder. Data primer yang dikumpulkan meliputi karakteristik rumah tangga kelapa sawit petani kecil, pengeluaran konsumsi makanan dan non makanan, pendapatan petani kelapa sawit petani kecil, dan luas lahan plasma dan non plasma. Data sekunder berasal dari instansi terkait seperti BPS, KP2KP, BPP Kabupaten Pangkalan Lada, Departemen Pertanian dan Peternakan. Data yang diperoleh dari lapangan diproses dari tabulasi dan dihitung menggunakan rumus PKP. Hasil penelitian menunjukkan bahwa berdasarkan tingkat kesejahteraan petani berdasarkan proporsi konsumsi makanan 39 rumah tangga petani, atau sekitar 90,7\% dari total sampel rumah tangga dalam kategori petani sejahtera dan 4 rumah tangga atau sekitar 9,3\% dalam kategori kurang mampu.
\end{abstract}

Katakunci : Rumah tangga, petani, sawit, konsumsi, makanan.

\section{ABSTRACT}

This study intends to discover the level of household welfare smallholder oil palm in Pangkalan Tiga Village Pangkalan Lada District Kotawaringin Barat Regency. The proportion of food consumption is one indicator to determine the level of household welfare. This study uses primary data and secondary data. Primary data collected include household characteristic smallholder oil palm, food and non food consumption expenditures, farmers income smallholder oil palm, and a land area of plasma and non plasma. Secondary data derived from relevant agencies such as BPS, KP2KP, BPP Pangkalan Lada District, Departement of Agriculture and Animal Husbandry. The data obtained from the field is processed in the from of tabulation and is calculated using the formula PKP. The results showed that based on the level of welfare of farmers based on the proportion of food comsumption 39 farmer households, or about $90,7 \%$ of the total sample of households in the category of prosperous farmers and 4 household or about $9,3 \%$ in the category of underprivileged.

Keywords: Households, farmers, oil palm, consumption, food.

\section{PENDAHULUAN}

Indonesia mempunyai potensi alamiah yang bagus untuk mengembangkan sektor agribisnis, termasuk tanaman perkebunan. Salah satu tanaman perkebunan yang di usahakan adalah tanaman perkebunan kelapa sawit. Hal ini disebabkan wilayah Indonesia yang terletak di daerah tropis di sekitar khatulistiwa, Indonesia memiliki beragam jenis tanah yang mampu menyuburkan tanaman, sinar matahari yang konsisten sepanjang tahun, keadaan iklim yang memenuhi persyaratan tumbuh tanaman, serta curah hujan rata-rata per tahun yang tinggi.

Pembangunan ekonomi jangka panjang tidak harus selalu diarahkan pada sektor industri, tetapi dapat juga diarahkan pada sektor lain, seperti sektor pertanian dan sektor jasa yang meliputi perdagangan, transportasi, komunikasi, perbankan dan lain-lain. Pembanguan ekonomi jangka 
panjang secara terpadu terpadu akan mengembangkan sumberdaya manusia yang dapat di perbaharui (Renewable Resources) melalui sektor pertanian, sektor agroindustri, sektor perdagangan, dan sektor jasa pendukung dalam kerangka pembangunan modal insane (Human Capital) Indonesia yang seluas-luasnya.

Pembangunan perkebunan kelapa sawit mempunyai dampak ganda terhadap ekonomi wilayah, terutama sekali dalam menciptakan kesempatan dan peluang kerja. Pembangunan perkebunan kelapa sawit ini telah memberikan tetesan manfaat (trickle down effect), sehingga dapat memperluas daya penyebaran (power of dispersion) pada masyarakat sekitarnya. Semakin berkembangnya perkebunan kelapa sawit, semakin terasa dampaknya terhadap tenaga kerja yang bekerja pada sektor perkebunan dan sektor turunannya. Dampak tersebut dapat dilihat dari peningkatan pendapatan masyarakat petani, sehingga meningkatnya daya beli masyarakat pedesaan, baik untuk kebutuhan primer maupun kebutuhan sekunder.

Pembangunan perkebunan kelapa sawit di daerah Kalimantan Tengah membawa perubahan besar terhadap keadaan masyarakat pedesaan, khususnya masyarakat pendatang (transmigrasi), karena program pembangunan perkebunan kelapa sawit pada awalnya dikaitkan dengan program transmigrasi. Di samping itu dengan berkembangnya perkebunan kelapa sawit juga merangsang tumbuhnya industri pengolahan yang bahan bakunya dari kelapa sawit. Kondisi ini menyebabkan tingginya mobilitas penduduk di Kalimantan Tengah terutama di daerah pengembangan perkebunan kelapa sawit.

Kotawaringin Barat memiliki potensi dalam pengembangan sektor pertanian khususnya sektor tanaman perkebunan. Hal ini dikarenakan potensi sumber daya alam yang tersedia cukup besar yang tercermin dalam produk Domestik Regional Bruto Tahun 2013. Peranan sektor pertanian pada tahun 2013 sebesar 40,82\% dengan kontribusi terbesar dari sub sektor tanaman perkebunan $34,35 \%$. Sub sektor tanaman perkebunan di Kotawaringin Barat didominasi oleh kelapa sawit. Luas areal perkebunan kelapa sawit yang semakin meningkat setiap tahunnya diimbangi dengan peningkatan produksinya, pada tahun 2011 produksi kelapa sawit rakyat tercatat sebesar 53,31 ribu ton dan pada tahun 2013 produksi kelapa sawit dari perkebunan rakyat tercatat 51,34 ribu ton. Luas areal perkebunan karet mengalami peningkatan dari 15.187 hektar menjadi 15.231 hektar pada tahun 2013 (BPS Kotawaringin Barat, 2014).

Konsumsi adalah pembelanjaan atas barang-barang dan jasa-jasa yang dilakukan oleh rumah tangga dengan tujuan untuk memenuhi kebutuhan dari orang yang melakukan pembelanjaan tersebut. Pembelanjaan masyarakat atas makanan, pakaian, dan barang-barang kebutuhan mereka yang lain digolongkan pembelanjaan atau konsumsi. Barang-barang yang di produksi digunakan oleh masyarakat untuk kebutuhannya dinamakan barang konsumsi (Cahyono 2003 dalam Ikhsan 2011).

Secara garis besar kebutuhan rumah tangga dapat dikelompokkan menjadi 2 kategori besar, yaitu kebutuhan pangan dan kebutuhan non pangan. Secara alamiah kuantitas pangan yang dibutuhkan seseorang akan mencapai titik maksimum sementara kebutuhuan non pangan tidak ada batasnya. Dengan demikian, besaran pendapatan yang dibelanjakan untuk pangan dari suatu rumah tangga dapat digunakan sebagai petunjuk tingkat kesejaheraan rumah tangga tersebut. Dengan kata lain, Semakin tinggi pengeluaran untuk pangan, semakin kurang kesejahteraan rumah tangga yang bersangkutan. Sebaliknya, semakin kecil pangsa pengeluaran pangan, maka rumah tangga tersebut semakin sejahtera (Mulyanto 2005 dalam Ikhsan 2011).

Pola pengeluaran konsumsi penduduk merupakan informasi untuk melihat kesejahteraan penduduk. Besarnya nilai nominal (dapat diukur dalam satuan uang) yang dibelanjakan baik dalam bentuk pangan maupun non pangan, secara tidak langsung dapat mencerminkan kemampuan ekonomi rumah tangga, untuk mencukupi kebutuhan yang mencakup barang dan jasa(http://repository.usu.ac.id/). 
Pendapatan rumah tangga petani kelapa sawit adalah seluruh pendapatan yang diperoleh oleh seluruh anggota rumah tangga tersebut, secara garis besar dapat di golongkan menjadi dua sumber pendapatan, yaitu (1) pendapatan yang berasal dari hasil kegiatan usaha tani kelapa sawit milik sendiri, dan (2) pendapatan dari luar kegiatan usaha tani kelapa sawit milik sendiri (Ikhsan, 2011).

Tujuan penelitian adalah untuk mengetahui tingkat kesejahtraan rumah tangga petani plasma kelapa sawit di Desa Pangkalan Tiga, Kecamatan Pangkalan Lada, Kabupaten Kotawaringin Barat.

Hasil penelitian ini diharapan dapat digunakan sebagai bahan pertimbangan ketika membuka lahan perkebunan kelapa sawit agar bisa memajukan perekonomian di sekitar desa serta sebagai laporan mengenai tingkat kesejahteraan masyarakat di Desa Pangkalan Tiga, Kecamatan Pangkalan Lada, Kabupaten Kotawaringin Barat.

\section{METODE PENELITIAN}

\section{Waktu dan Tempat}

Kegiatan penelitian ini dilakukan selama 3 (tiga) bulan, yaitu mulai bulan November 2014 sampai dengan Januari 2015. Tempat penelitian ini adalah di Desa Pangkalan Tiga Kecamatan Pangkalan Lada Kabupaten Kotawaringin Barat.

\section{Jenis, Sumber dan Metode Pengumpulan Data}

Jenis data yang diperlukan dalam penelitian ini adalah data kualitatif dan kuantitatif. Data yang dipergunakan dakam penelitian ini adalah data primer dan data sekunder. Metode pengumpulan data yang digunakan dalam penelitian ini adalah survei dan wawancara.

\section{Metode Penentuan Sampel}

Penetapan Desa Pangkalan Tiga sebagai lokasi penelitian dilakukan secara sengaja (purposive). Metode yang digunakan untuk menentukan sampel adalah secara Random Sampling, untuk menentukan jumlah sampel diambil $10 \%$ dari jumlah populasi. Jumlah populasi petani plasma ada
435, maka diambil $10 \%$ dari total populasi tersebut menjadi 43 sampel petani plasma.

\section{Analisis Data}

Analisis data yang dilakukan sesuai dengan tujuan penelitian. Guna menganilisis tujuan untuk mengetahui tingkat kesejahteraan melalui pendekatan pola konsumsi rumah tangga petani plasma kelapa sawit di Desa Pangkalan Tiga Kecamatan Pangkalan Tiga Kabupaten Kotawaringin Barat, dilakukan analisis deskriptif yaitu mendeskripsikan pola konsumsi rumah tangga (pangan dan non pangan) dengan kriteria kesejahteraan ke dalam bentuk uraian kalimat. Rumah tangga diklasifikasikan sebagai rumah tangga yang sejahtera apabila pengeluaran pangan $<50 \%$ dari total pengeluaran. Pengeluaran konsumsi pangan sebanyak $50 \%$ - $60 \%$ dari total pengeluaran dikatakan petani pra sejahtera. Pengeluaran konsumsi pangan sebanyak $>60 \%$ dari total pengeluaran dikatakan petani tidak sejahtera (Akmal 2005 dalam Ikhsan 2011).

Proporosi Konsumsi Pangan (PKP) adalah perbandingan pengeluaran pangan dengan total pengeluaran konsumsi (pangan + non pangan). Menurut Ilham dan Sinaga (2002) Proporsi Konsumsi Pangan (PKP) dapat di hitung menggunakan rumus:

Keterangan:

$$
P K P=\frac{P P}{P P+P N P} \times 100 \%
$$

$$
\begin{array}{ll}
\mathrm{PKP} & =\text { Proprosi Konsumsi Pangan } \\
\mathrm{PP} & =\text { Pengeluaran Pangan } \\
\mathrm{PNP} & =\text { Pengeluaran Non Pangan }
\end{array}
$$

Proporsi konsumsi non pangan adalah perbandingan pengeluaran non pangan dengan total pengeluaran konsumsi (pangan + non pangan). Menurut Ilham dan Sinaga (2002) dalam Ilham dan Sinaga (2013) Proporsi Konsumsi Non Pangan (PKNP) dapat dihitung dengan rumus :

Keterangan:

$$
P K N P=\frac{P N P}{P P+P N P} \times 100 \%
$$

$$
\begin{aligned}
& \text { PKNP = Proporsi Konsumsi Non } \text { Pangan } \\
& \text { PP }=\text { Pengeluaran Pangan } \\
& \text { PNP }=\text { Pengeluaran Non Pangan }
\end{aligned}
$$

HASIL DAN PEMBAHASAN 
Berdasarkan hasil penelitian penerimaan rumah tangga petani plasma terdiri dari penerimaan yang berasal dari plasma, non plasma, usahatani dan non usahatani.
Ditinjau dari struktur penerimannnya, kontribusi penerimaan dari plasma lebih kecil daripada penerimaan di luar plasma. Untuk lebih jelasnya dapat dilihat pada Tabel 1 dibawah ini.

Tabel 1. Rata-Rata Penerimaan Rumah Tangga Petani Plasma Kelapa Sawit di Desa Pangkalan Tiga Kecamatan Pangkalan Lada

\begin{tabular}{ccccc}
\hline No & Jenis Penerimaan Petani & $\begin{array}{c}\text { Jumlah } \\
(\mathrm{Rp}) / \text { Tahun }\end{array}$ & $\begin{array}{c}\text { Jumlah } \\
(\mathrm{Rp}) / \text { Bulan }\end{array}$ & Prosentase (\%) \\
\hline 1 & Plasma & $40.470 .325,58$ & $3.372 .527,13$ & 46,78 \\
2 & Non Plasma & $21.537 .209,30$ & $1.794 .767,44$ & 24,90 \\
3 & Usahatani & $2.495 .302,33$ & $207.941,86$ & 2,88 \\
4 & Non Usahatani & $22.003 .752,56$ & $1.833 .646,05$ & 25,44 \\
\hline & Jumlah & $86.506 .589,77$ & $7.208 .882,48$ & 100 \\
\hline
\end{tabular}

Berdasarkan Tabel 1 diatas terlihat penerimaan petani plasma setiap bulannya rata-rata adalah $\mathrm{Rp} 7.208 .882,48,-$. Penerimaan terbesar berasal dari plasma yang kemudian diikuti oleh penerimaan yang berasal dari non usahatani, non plasma dan usahatani. Penerimaan petani yang berasal dari luar plasma (non plasma, usahatani, non usahatani) lebih besar dibandingkan penerimaan yang bersala dari plasma. Penerimaan yang berasal dari plasma hanya sebesar $46,78 \%$ dari penerimaan total petani plasma, sedangkan $53,22 \%$ nya berasal dari non plasma, usahatani dan non usahatani. ini mengindikasikan bahwa petani yang menjadi plasma perkebunan kelapa sawit rata-rata mempunyai usaha yang lain atau sampingan dari usaha utamanya sebagai petani plasma. Usaha sampingan yang dilakukan oleh petani plasma meliputi sebagai buruh, karyawan perusahaan kelapa sawit, petani dan pedagang.

Tabel 2. Rata-Rata Pengeluaran Pangan dan Non Pangan Rumah Tangga Petani Plasma Kelapa Sawit di Desa Pangkalan Tiga Kecamatan Pangkalan Lada

\begin{tabular}{clccc}
\hline No & Jenis Pengeluaran & $\begin{array}{c}\text { Jumlah } \\
(\mathrm{Rp}) / \text { Tahun }\end{array}$ & $\begin{array}{c}\text { Jumlah } \\
(\mathrm{Rp}) / \mathrm{Bulan}\end{array}$ & $\begin{array}{c}\text { Prosentase } \\
(\%)\end{array}$ \\
\hline 1 & Pangan & $18.621 .623,26$ & $1.551 .801,94$ & 21,53 \\
2 & Non Pangan & $67.884 .966,51$ & $5.657 .080,54$ & 78,47 \\
\hline & Jumlah & $86.506 .589,77$ & $7.208 .882,48$ & 100,00 \\
\hline
\end{tabular}

Dari Tabel 2 diatas, terlihat bahwa ratarata pengeluaran pangan pada rumah tangga petani plasma setiap tahunnya adalah $\mathrm{Rp}$. 18.621.623,26,- atau Rp. 1.551.801,94,setiap bulannya. Rata-rata pengeluaran non pangan pada rumah tangga petani plasma setiap tahunnya adalah Rp.67.884.966,51,-atau Rp. 5.657.080,54,- setiap bulannya. Rata-rata pengeluaran non pangan pada rumah tangga petani plasma lebih besar bila dibandingkan dengan rata-rata pengeluaran pangan, hal ini disebabkan karena pada setiap bulannya petani plasma menabung dengan rata-rata setiap tahunnya $\mathrm{Rp}$. 56.202.151,72 atau Rp. 4.683.512,64 setiap bulannya. Selain dipergunakan untuk menabung, pengeluaran non pangan pada rumah tangga petani plasma meliputi biaya kesehatan, biaya pendidikan dan kuliah anak, serta pembelian kendaraan bermotor. Kebutuhan kendaraan bermotor sangat diperlukan untuk usaha kelapa sawit dan untuk kendaraan pendidikan anak, karena setiap anaknya yang akan sekolah SMP atau SMA akan dibelikan orang tuanya alat transportasi seperti sepeda motor. Hal ini terlihat dari rata-rata kepemilikan sepeda motor dari setiap rumah tangga \pm 2 unit. 
Rata-rata proporsi konsumsi pangan (PKP) pada rumah tangga petani plasma sebesar $21,53 \%$ dan rata-rata proporsi konsumsi non pangan (PKNP) pada rumah tangga petani plasma adalah $73,47 \%$.

Untuk mengetahui tingkat kesejahteraan rumah tangga petani plasma berdasarkan proporsi konsumsi pangan (PKP) dan proporsi konsumsi non pangan (PKNP), rumah tangga petani palsma yang sejahtera sebanyak 39 rumah tangga dan rumah tangga petani plasmayang pra sejahtera sebanyak 4 rumah tangga. Untuk lebih jelasnya dapat dilihat pada Tabel 3, dibawah ini.

Tabel 3. Persentase Tingkat Kesejahteraan Rumah Tangga Petani Plasma Berdasarkan Proporsi Konsumsi Pangan (PKP)

\begin{tabular}{llcc}
\hline \multirow{2}{*}{ PKP $(\%)$} & \multirow{2}{*}{ Kriteria Kesejahteraan } & \multicolumn{2}{c}{ Jumlah Rumah Tangga Petani Sampel } \\
\cline { 3 - 4 } & & $($ Orang) & $(\%)$ \\
\hline$<50$ & RT Sejahtera & 39 & 90,7 \\
$50-60$ & RT Pra Sejahtera & 4 & 9,3 \\
$>60 \%$ & RT tidak Sejahtera & - & 100 \\
\hline Total & & 43 & \\
\hline
\end{tabular}

Berdasarkan Tabel 3, diketahui bahwa rumah tangga petani plasma kelapa sawit yang sejahtera adalah 39 rumah tangga atau sekitar 90,7\% dari 43 sampel rumah tangga petani plasma kelapa sawit plasma, dan selebihnya merupakan rumah tangga yang pra sejahtera yaitu 4 rumah tangga atau sekitar 9,3\% dari total jumlah sampel. Rumah tangga petani plasma yang termasuk dalam kategori sejahtera apabila proporsi pengeluaran pangan (PKP) nya kurang dari $50 \%$ dan rumah tangga yang termasuk dalam kategori pra sejahtera apabila proporsi pengeluaran pangan (PKP) nya antara 50\%$60 \%$, hal ini sesuai dengan pendapat Akmal (2005), yang menyatakan bahwa klasifikasi petani dikatakan sejahtera apabila proporsi pengeluaran pangan (PKP) lebih kecil dari $50 \%$ dari total pengeluaran pangan dan petani dikatakan pra sejahtera apabila proporsi pengeluaran pangan (PKP) nya antara 50\%$60 \%$.

\section{KESIMPULAN}

Berdasarkan hasil penelitian menunjukkan bahwa tingkat kesejahteraan petani plasma berdasarkan proporsi konsumsi pangan (PKP) 39 rumah tangga petani atau sekitar $90,7 \%$ dari total sampel rumah tangga petani dalam kategori sejahtera dan 4 rumah tangga petani atau sekitar 9,3 $\%$ dalam keadaan pra sejahtera.

\section{DAFTAR PUSTAKA}

Akmal. 2005. Analisis pola konsumsi keluarga di Kecamatan Tallo Kota Makassar. Tesis Magister Sains. Program Pascasarjana, Universitas Hassanudin, Makasar.

BPS Kotawaringin Barat. Statistik Kobar 2013. Pangkalan Bun.

Ikhsan, Nur. 2011. Tingkat kesejahteraan petani kelapa sawit di Desa Mekar Mulya Kecamatan Sematu Jaya Kabupaten Lamandau. Skripsi Fakultas Pertanian, Jurusan Sosial Ekonomi Pertanian. Universitas Palangka Raya.

Ilham dan Sinaga. 2013. Penggunaan pangsa dan pengeluaran pangan sebagai indikator komposit ketahanan pangan. http://ejournal.unud.ac.id.). Diakses tanggal 28 Desember 2014. 